\title{
Comparison of efficiency between i-gel blind intubation and i-gel-assisted bronchoscopic intubation during cardiopulmonary resuscitation: randomized simulation study
}

W Kim*, HY Choi, YS Jang, GH Kang

From ESICM LIVES 2015

Berlin, Germany. 3-7 October 2015

\section{Introduction}

i-gel has been used as a conduit for blind and bronchoscopic operative intubation. However, it is not easy that conventional polyvinyl chloride (PVC) tracheal tube pass through i-gel in emergent intubation during cardiopulmonary resuscitation. We considered wire-reinforced silicone tube could pass through i-gel more easily than conventional PVC tube.

\section{Objectives}

This study aimed to compare intubation performances among i-gel blind intubation (IGI), i-gel bronchoscopic intubation (IBRI) and intubation using Macintosh laryngoscope (MCL) applying two kinds of endotracheal tube during chest compressions. We hypothesized that IGI using wire-reinforced silicone tube could achieve tracheal intubation most rapidly and successfully.

\section{Methods}

In 23 emergency physicians, a prospective randomized crossover study was conducted to examine the three intubation techniques using two kinds of endotracheal tube. Primary outcomes were the intubation time. Secondary outcomes were the cumulative success rate for intubation.

\section{Results}

The mean intubation time using IGI was shorter $(p<$ 0.017) than that of IBRI and MCL in both endotracheal tubes (17.6 vs. 29.3 vs. 20.2 in conventional PVC tube; 14.6 vs. 27.4 vs. 19.9 in wire-reinforced silicone tube; sec).
There were no significant $(p>0.05)$ differences between conventional PVC and wire-reinforced silicone tube for each intubation technique. The cumulative success rate using IGI was also shorter $(p<0.017)$ than that of IBRI and MCL in both endotracheal tubes.

\section{Conclusions}

IGI could be an effective intubation technique in emergent intubation during cardiopulmonary resuscitation.

Published: 1 October 2015

\section{References}

1. de Lloyd LJ, Subash F, Wilkes AR, Hodzovic I: A comparison of fibreopticguided tracheal intubation through the Ambu ${ }^{\oplus}$ Aura-i ${ }^{\mathrm{T}}$, the intubating laryngeal mask airway and the i-gel ${ }^{\mathrm{Tm}}$ : a manikin study. Anaesthesia 2015, 70(5):591-597.

2. Gatward JJ, Thomas MJ, Nolan JP, Cook TM: Effect of chest compressions on the time taken to insert airway devices in a manikin. $\mathrm{Br} J$ Anaesth 2008, 100(3):351-356.

3. Gatward JJ, Cook TM, Seller C, Handel J, Simpson T, Vanek V, Kelly F: Evaluation of the size $4 \mathrm{i}$-gel airway in one hundred non-paralysed patients. Anaesthesia 2008, 63(10):1124-1130.

4. Jackson KM, Cook TM: Evaluation of four airway training manikins as patient simulators for the insertion of eight types of supraglottic airway devices. Anaesthesia 2007, 62(4):388-393.

doi:10.1186/2197-425X-3-S1-A547

Cite this article as: Kim et al:: Comparison of efficiency between i-gel blind intubation and i-gel-assisted bronchoscopic intubation during cardiopulmonary resuscitation: randomized simulation study. Intensive Care Medicine Experimental 2015 3(Suppl 1):A547. 